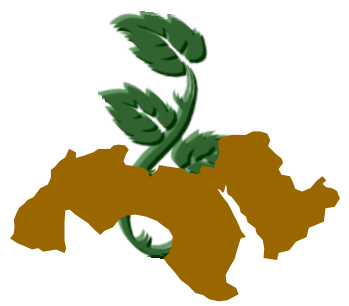

Arab Univ. J. Agric. Sci., Ain Shams Univ., Cairo, 15(2), 315-324, 2007

\title{
BIOCHEMICAL AND MOLECULAR CHARACTERIZATION OF SOME YEAST ISOLATES
}

\author{
Abulhamd', A.; M.M. Mokhtar $^{2}$ and Farrag, Rasha, Mohamed ${ }^{2}$ \\ 1. Department of Botany and Microbiology, Faculty of Science, Al-Azhar University, Cairo, Egypt \\ 2. The Regional Center for Mycology and Biotechnology, Al-Azhar University, Cairo, Egypt
}

Keywords: Primer; Saccharomyces cerevisiae; Isolation; DNA; Tree diagram

\begin{abstract}
Sixteen yeast isolates from various sources including molasses, foodstuffs, concentrated juices and soils were identified using simplified API 20 C AUX yeast identification system and random amplified polymorphic DNA-polymerase chain reaction (RAPD-PCR). The isolates were found to belong to 11 species; Candida famata, C. glabrata, C. krusei / inconspicua, C. norvegensis, C. colliculosa, Cryptococcus humicolus, Rhodotorula mucilaginosa, Kloeckera spp., Geotrichum capitatum and Saccharomyces cerevisiae. API and RAPD-PCR proved to be useful and convenient taxonomic tools for rapid identification at the species level, proving that at least two techniques are needed for precise identification. RAPD-PCR procedure is faster than traditional characterization techniques; the identification of a single colony was typically achieved in less than $10 \mathrm{hr}$.
\end{abstract}

\section{INTRODUCTION}

Various molecular techniques have been developed which permit species identification and typing of food-borne microorganisms, including yeast. Pulsed-field gel electrophoresis (PFGE; karyotyping), restriction enzyme analysis, PCRbased techniques, sequencing (Deák, 1995; Van der Vossen \& Hofstra 1996; Smole and Raspor, 1997) and Southern hybridization with moderately repetitive DNA probes (Odds et al 1992 and Espinel-Ingroff $\boldsymbol{e t}$ al 1999) are among the technique used. Some of these techniques have been applied successfully to characterize yeast isolated from various food products; however, most are too so- phisticated or cumbersome for use in routine industrial practice.

In recent years, PCR-based techniques targeting ribosomal RNA genes that can be performed with relative ease have emerged. Of these, restriction analysis of variable internal transcribed spacer (ITS) sequences framing the more conservative 5.8S rRNA gene (rDNA) has proven most useful, allowing both species identification and typing of isolates (Valente et al 1997; Guillamón et al 1998 and Fernández et al 1999). Based on an extensive database, this technique has been proposed for rapid and routine identification of yeast (Esteve-Zarzoso et al 1999).

The most frequently used PCR-based technique currently in use is random amplified polymorphic DNA-PCR (RAPD-PCR) which has been described by Williams et al (1990). In this technique, single or a pair wise combination of primers, typically 9 to 10 nucleotides in length, are used to amplify target genomic DNA by polymerase chain reaction (PCR). Fragments of DNA are generated by PCR amplification if the primer target sites for the primer happen to occur within approximately $5 \mathrm{~kb}$ of each other on opposite DNA strands.

A similar procedure was simultaneously discovered by Welsh and McClelland (1990), who called it arbitrary primed-PCR. This procedure results in the amplification of small segments of the bacterial genome, the size and pattern of the fragments are characteristic of the bacterial species. The amplified products, which form strainspecific fingerprints, are then analyzed by separation through an agarose gel and ethidium bromide stained.

Specific PCR amplification of the $5 \mathrm{~S}$ and $16 \mathrm{~S}$ rRNA genes has been used to detect lactic acid bacteria in beer (DiMichele \& Lewis, 1993 and Tompkins et al 1996). Tsuchiya et al (1994) have 
combined the specific PCR with temperature gradient gel electrophoresis to identify lactic acid bacteria. RAPD-PCR technology can also be used for the identification of non-brewing yeast without changes to the procedure (Lieckfeldt et al 1993).

Randomly amplified polymorphic DNA (RAPD) analysis seemed to be efficient in distinguishing different isolates; it has a high discriminatory power, it is easy to perform, does not require radiolabelled probes, and it is applicable to several microorganisms (Robert et al 1995). It can be used to reliably type yeast strains (Baleiras et al 1995 \& 1996 and Molnár et al 1995).

The major advantage of using RAPD-PCR technology is that a pure single colony can be identified by its fingerprint pattern in less than one day. In the fermentation industry, this procedure has been useful for the characterization of different isolates of yeast (Lieckfeldt et al 1993 and Grando et al 1994), the identification of Obesumbacterium proteus (Savard et al 1994), the investigation of barley variants (Ko and Henry, 1994), and the identification of hopleaf tissue (Abbott and Fedele, 1994). Obesumbacterium proteus has also been differentiated using a PCR technique called enteric repetitive intergenic consensus-PCR (ERIC-PCR) (Prest et al 1994).

Another advantage of the RAPD-PCR for the identification of microorganisms is that the identification is based on the genotype rather than the phenotype. Phenotypic identification is the basis of identification by other "rapid" methods, such as the API system or the Biolog GN microplate system, which rely on the metabolic activity of a microbe.

In this study, RAPD-PCR was applied to confirm the identification of several yeast isolates from different sources by API system. The ability to differentiate rapidly between a pure colony isolate of yeast among contaminants within one working day represents a significant improvement in reducing hold times while traditional phenotypic characterization is undertaken. In addition, this technology has application at any location where pure colony isolates are routinely obtained by traditional plating methods.

\section{MATERIALS AND METHODS}

\section{Isolation and culture media}

Isolation and subculturing of the yeast isolates were performed on different media including yeast extract peptone dextrose (YPD) broth medium (glucose, 10; yeast extract, 3; peptone, $3 \mathrm{~g} / \mathrm{L}$ ), yeast extract peptone dextrose (YPD) agar medium (YPD broth $+15 \mathrm{~g}$ agar), yeast extract Malt extract (YM) broth medium (glucose, 10; yeast extract, 3; peptone, 3; malt extract, $3 \mathrm{~g} / \mathrm{L}$ ) and Yeast extract Malt extract (YM) agar medium (YM broth $+15 \mathrm{~g}$ agar). $\mathrm{pH}$ of the media was adjusted at 4.5. The investigated yeast isolates were isolated from molasses, foodstuffs, concentrated juices and soils. Samples were introduced into YPD and YM broth media and incubated at $28^{\circ} \mathrm{C}$ for $24 \mathrm{hr}$. The samples were diluted $10^{4}, 10^{6}$ and $10^{8}$ fold with distilled water and then $0.1 \mathrm{ml}$ of dilutes were plated onto YPD and YM agar media. After incubation at $28^{\circ} \mathrm{C}$, the appearing yeast colonies were purified. Saccharomyces cerevisiae TCY1 (MAT $\propto$ lys2 ura3), was the used type strain (Abul-Hamd, 1999).

\section{Biochemical identification of yeast}

The API 20 C AUX yeast identification system (BioMerieux Vitek, Inc., Hazelwood, Mo) was used for biochemical identification of the yeast isolates. The system consist of a disposable plastic strip with twenty cupules containing dehydrated reagents sufficient for 18 biochemical tests, a negative control and a couple containing glucose as positive control along the reaction. Suspensions were made by picking up a separate colony for each isolate from $48-72 \mathrm{hr}$ agar plates and were added to the provided medium. Suspensions were used to fill the cupules of the test strips as directed by the provider. All test strips were incubated ed at $30^{\circ} \mathrm{C}$ and the growth was recorded after 48 and $72 \mathrm{hr}$. Based on the observed reactions, a profile number was generated for each isolate. Identification was made by reference to the API analytical profile index.

\section{DNA extraction}

The investigated yeast isolates were grown on YPD agar plates at $28^{\circ} \mathrm{C}$ for 24 to $48 \mathrm{hr}$. A single colony was then subcultured overnight on YPD broth medium and incubated at $28^{\circ} \mathrm{C}$ with shaking at $200 \mathrm{rpm}$. DNA was extracted from this culture by an existing protocol (Lehmann et al 1992). Yeast DNA extract could be stabilized by precipitating the nucleic acids with two volumes of ethanol for $3 \mathrm{hr}$ at $-20^{\circ} \mathrm{C}$. The yeast nucleic acid precipitate was collected by pelleting in a microfuge, and the supernatant was decanted and discarded. The nucleic acid pellet was dried briefly under 
vacuum then resuspended in $1 \mathrm{ml}$ of sterile water.

DNA concentrations were determined spectrophotometrically with a spectrophotometer (Lambda 1A; Perkin-Elmer). DNA purity was determined by $A_{260} / A_{280}$ ratio and 1.8 to 2.1 was considered acceptable.

\section{RAPD-PCR}

The two primers used in this study, primer 1 (5'-GGTGCGGGAA) and primer 6 (5'-CCCGTCAGCA) were purchased from Amershambioscience. Amplification reaction solutions were prepared in a final volume of $50 \mu \mathrm{l}$ containing $10 \mathrm{mM}$ Tris- $\mathrm{HCl}, \mathrm{pH} 8.3,1.5 \mathrm{mM} \mathrm{MgCl} 2,50$ $\mathrm{mM} \mathrm{KCl}$, and $100 \mathrm{M}$ each of dATP, dGTP, dCTP, and dTTP (Boehringer Mannheim), 2.5 M primer, 1.25 units of Taq DNA Polymerase (Boehringer Mannheim) and approximately $50 \mathrm{ng}$ of DNA. The amplification was performed in an MJ Research programmable thermal cycler (PTC100/60) where the program was as follows: universal denaturation cycle $\left(5 \mathrm{~min}\right.$ at $\left.94^{\circ} \mathrm{C}\right), 45 \mathrm{cy}-$ cles of annealing/extension reactions ( $1 \mathrm{~min}$ at $94^{\circ} \mathrm{C}, 1 \mathrm{~min}$ at an optimum annealing temperature $36^{\circ} \mathrm{C}$ for each used universal primer and $2 \mathrm{~min}$ at $72^{\circ} \mathrm{C}$ ) and cycle of final extension step ( $5 \mathrm{~min}$ at $72^{\circ} \mathrm{C}$ ) was followed by soaking at $4^{\circ} \mathrm{C}$.

\section{Horizontal Gel Electrophoresis}

RAPD-PCR-amplified products were separated by agarose gel electrophoresis using a horizontal submarine gel system (E-C Apparatus Corp., Holbrook, N.Y.). Agarose (Gibco BRL Life Technologies) at a concentration of $2 \%$ (wt/vol) was used to separate RAPD products. Electrophoresis was conducted in $0.5 \times \mathrm{TBE}$ buffer $(5.4 \mathrm{~g}$ of Tris base, $2.75 \mathrm{~g}$ of boric acid, and $2 \mathrm{ml}$ of $0.5 \mathrm{M}$ EDTA [pH 8.0] in 1 liter of distilled water) at $10 \mathrm{~V} / \mathrm{cm}$ for various times, depending on the size of the gel unit; DNA size markers (Boehringer XII and XIV) were used as standards. DNA bands were stained with ethidium bromide $(10 \mathrm{mg} / \mathrm{ml})$ and then visualized and photographed under UV light using a Gel Doc.2000 Transilluminator (Bio$\mathrm{Rad})$.

\section{Cluster analysis}

Genetic relationships and divergence between RAPD patterns of the yeast isolates were calculated from the Pearson coefficient using Bio-Rad Molecular Analyst software (Anonymous, 1999) and are illustrated in a dendrogram constructed using the unweighted pair-group method with arithmetic averaging (UPGMA) and single linkage.

\section{RESULTS}

\section{Isolation and identification of yeast isolates}

Sixteen yeast isolates (symbolized 2-17) were subcultured and purified on Yeast extract peptone dextrose (YPD) agar medium and Yeast-Malt extract media. The Yeast isolates were isolated form molasses, foodstuffs, concentrated juices and soils. The API $20 \mathrm{C}$ AUX yeast identification system was used for identification of the sixteen yeast isolates. The yeast identification system (API $20 \mathrm{C}$ AUX) confirmed that the sixteen yeast isolates belong to Candida famata (isolate 16), C. glabrata (3 isolates; 3, 6, 15), C. krusei / inconspicua (2 isolates; 13,17$), C$. norvegensis (isolate 5), $C$. colliculosa (2 isolates; $9 \& 10)$, and Cryptococcus humicolus (isolate 14), Rhodotorula mucilaginosa (isolate 12), Kloeckera spp. (2 isolates; 4 \& 7) and Geotrichum capitatum (2 isolate; 8 \& 11) and Saccharomyces cerevisia, TCY1 (lane 2 in Fig. 1 and 3)

\section{RAPD reaction}

Two oligonucleotide primers were tested for their ability to generate RAPD markers from genomic DNAs of sixteen yeast strains.

Figures (1 and 3) illustrate random amplified polymorphic DNA-polymerase chain reaction (RAPD-PCR) fingerprint patterns of the yeast isolates with both primers. Lane 2, Saccharomyces cerevisiae, TCY1; Lanes 3, 6 \&15, Candida glabrata; Lanes 4 \& 7, Kloeckera spp.; Lane 5, C. norvegensis; Lanes 8 \& 11, Geotrichum capitatum; Lanes 9 \& 10, C. colliculosa; Lane 12, Rhodotorula mucilaginosa; Lanes 13, 17, C. krusei / inconspicua; Lane 14, Cryptococcus humicolus; Lane 16, Candida famata (Figs. 1 and 2). Lane 1 represents 250 bp ladder (Figs. 1 and 3) as DNA size standard.

The developed bands with various molecular weights were subjected to statistical analysis where the phylogenetic relationship among the biochemically-identified yeast isolates was investigated using a tree diagram with Euclidean distances and dice coefficient being the joining metric and the calculation method respectively. Figure (2) represents the tree diagram for DNA bands amplified by primer- 1 . 


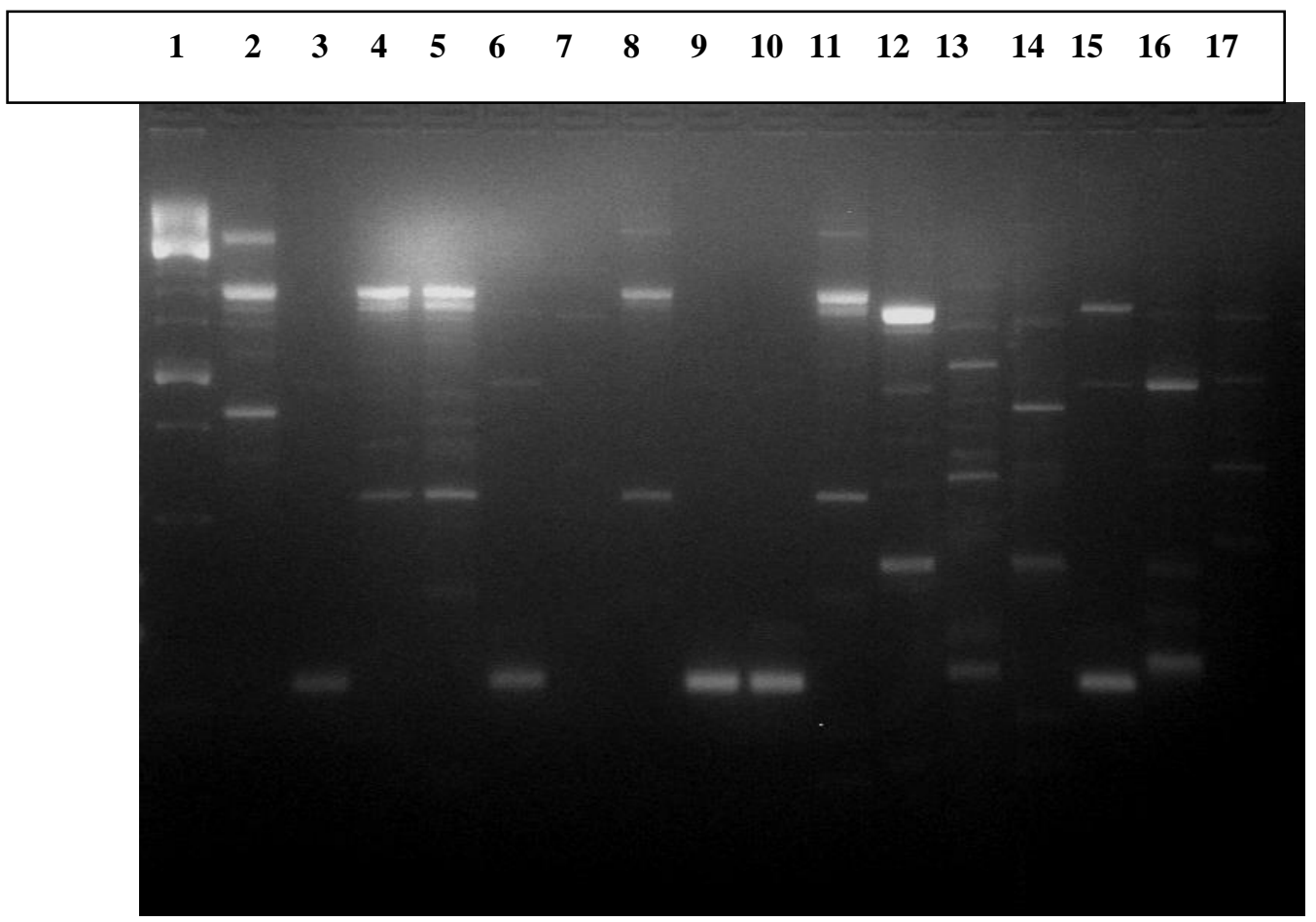

Figure 1. Banding pattern of RAPD- PCR of yeast isolates using primer-1.

Lane 1, 250bp ladder; Lane 2, Saccharomyces cerevisia, TCY1; Lanes 3-17 yeast isolates.

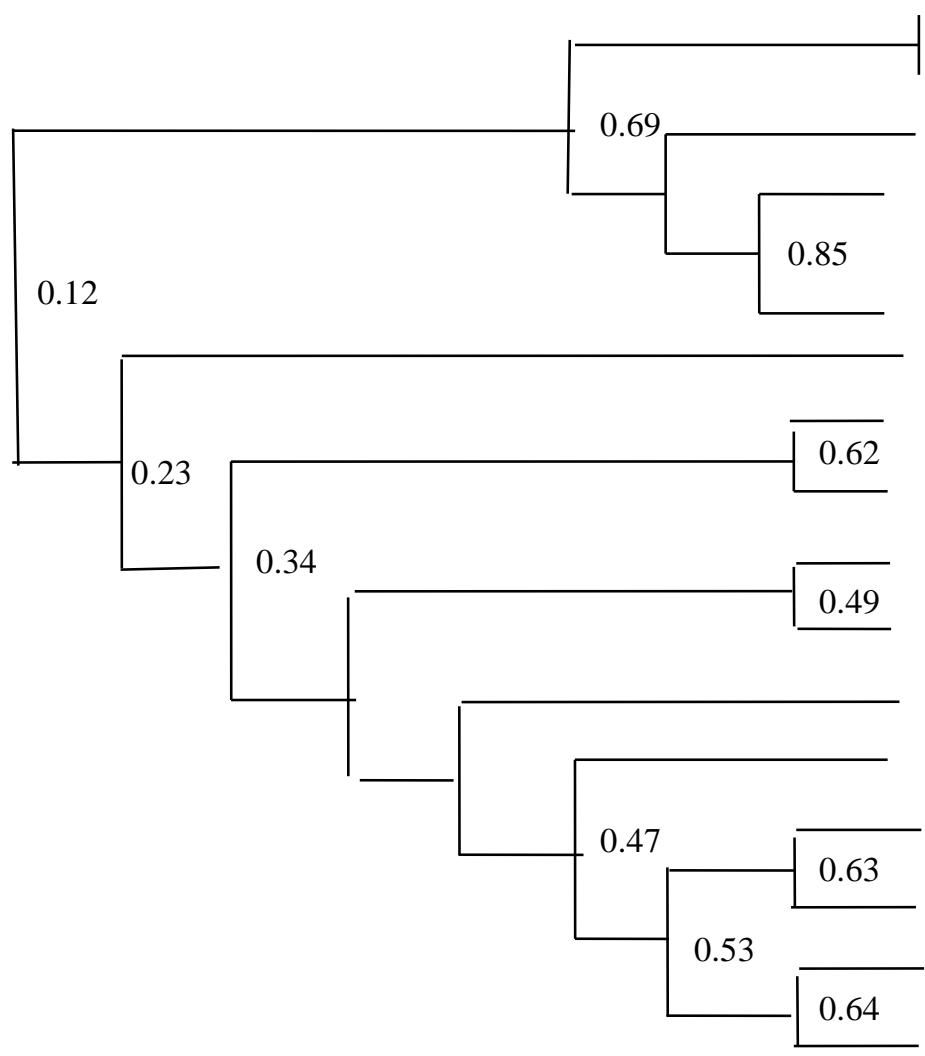
C. colliculosa (10)
C. colliculosa (9)
C. glabrata (15)
C. glabrata (6)
C. glabrata (3)
S. cerevisiae (2)
G. capitatum (11)
G. capitatum (8)

Cryp. humicolus (14)

R. mucilaginosa (12)

C. famata (16)

C. norvegensis (5)

C. krusei (13)

Klopckera sp. (4)

C. krusei (17)

Fig. 2. Dendrogram of the yeast isolates based on the similarity matrix of RAPD analysis using primer-1. 
Figure 3. Banding pattern of RAPD- PCR of yeast isolates using primer-6 Lane 1, 250bp ladder; Lane 2, Saccharomyces cerevisiae, TCY1; Lanes 3-17 yeast isolates.

The tree diagram classifies the investigated yeasts into four clades (groups). Clade one includes five yeasts of Candida glabrata (3 isolates; $3,6,15$ and $C$. colliculosa 2 isolates; $9 \& 10$ ) with two of which (isolates; 9 and 10) being identical; their similarity matrix is 100 (a linkage distance of one). The two strains of C. glabrata, 3 and 6, follows $C$. colliculosa, 9 and 10 in linkage where they are joined together by a distance of 0.85 . $C$. glabrata, 15 is linked to the other two strains belonging to the same organism C. glabrata (3 and 6) by a distance of 0.84 and 0.80 respectively, while joined to $C$. colliculosa, 9 and 10 at a distance of 0.69 . Isolates of this clade are linked to the rest of the yeasts investigated by a distance of 0.12 .

The two isolates 8 and 11 of Geotrichum capitatum represent clade two, they are linked together at a distance of 0.62. Clade two is the nearest clade to isolate 2 (Saccharomyces cerevisiae TCY1) being linked at a distance of 0.23 . Clade three includes isolates Cryptococcus humicolus (isolate 14), Rhodotorula mucilaginosa (isolate 12), linked together at a distance of 0.49 . Clade three is linked to clade two at a distance of 0.34 , while linked to the last clade (clade four) at an average distance of 0.40 .
Clade four is represented by six isolates of Kloeckera spp. (isolates 4 \& 7); Candida krusei / inconspicua (isolates 13, 17); C. norvegensis (isolate 5), and Candida famata (isolate 16). In clade four, 7 (Kloeckera sp.) and 17 (Candida krusei / inconspicua) are the most related to each other (joined by a distance of 0.64) followed by 13 (Candida krusei / inconspicua) and (Kloeckera sp.) 4 (linked by a distance of 0.63 ), the last two isolates are joined to 7 (Kloeckera sp.) and 17 (Candida krusei / inconspicua) at a distance of 0.53 , with all these four isolates being joined to $C$. norvegensis (isolate 5), at a distance of 0.47. Candida famata, isolate 16 is the least related isolate to isolates of clade four being joined to all of them at an average distance of 0.37 .

Figure (4) illustrates the tree diagram developed from the amplified DNA fragments by primer 6 . The relationship among the isolates developed by primer six are more or less close to that developed by primer one. From Figure (4), three clades could be observed, clade one includes five isolates of Candida glabrata (isolates 3, 6, 15) and C. colliculosa (isolates $9 \& 10$; the same isolates forming clade one in case of primer one with differences in the values of the joining distances). The two strains belonging to Candida glabrata (3 and 6) are the most closely related 


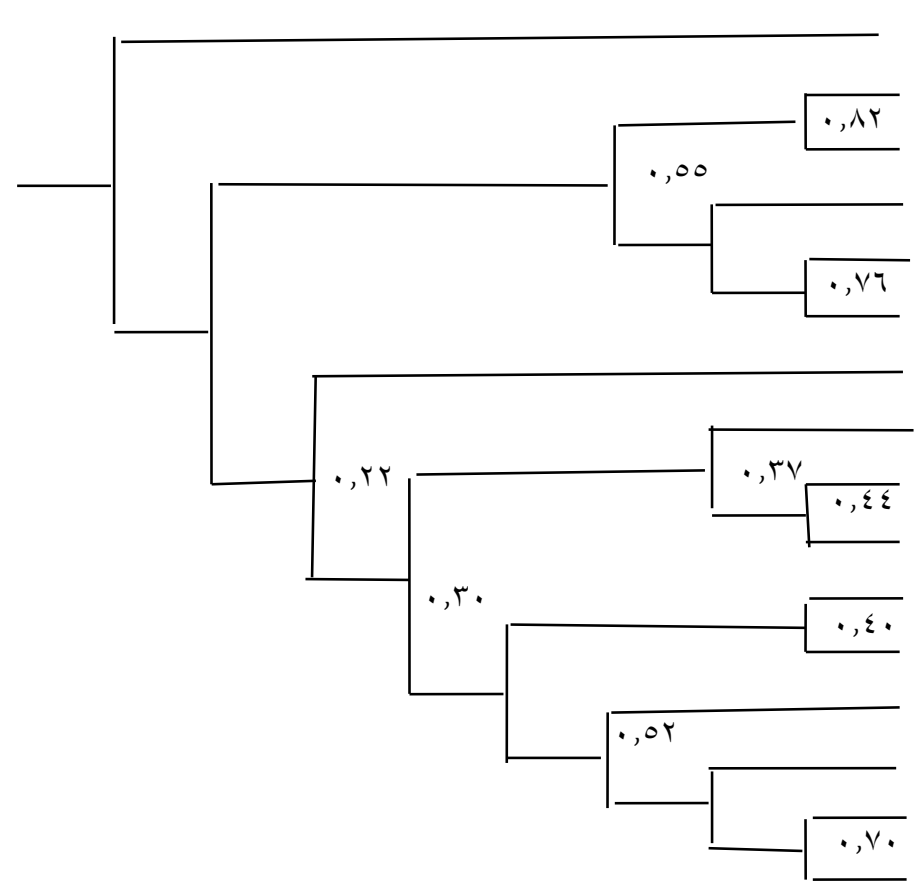

C. glabrata (6)

C. glabrata $\left({ }^{(}\right)$

C. glabrata (10)

C. colliculosa (10)

C. colliculosa (9)

C. krusei (13)

Klopckera sp. (7)

Cryp. humicolus (14)

S. cerevisiae (2)

C. krusei (17)

C. famata (16)

Klopckera sp. (4)

G. capitatum (8)

G. capitatum (11)

C. norvegensis (5)

Figure. 4. Dendrogram of the yeast isolates based on the similarity matrix of RAPD analysis using primer- 6 .

isolates in case of primer 6 where they are joined together by a distance of 0.82 . ), C. colliculosa (isolates $9 \& 10$ ) follows Candida glabrata (3 and 6) for being joined at a distance of 0.76. Candida glabrata, 15 is linked to $C$. colliculosa (isolates 9 $\& 10)$ by an average distance of 0.66 , while joined to Candida glabrata (3 and 6) at an average distance of 0.55 . Isolates of this clade are linked to the rest of the isolates investigated at an average distance of 0.04 representing the uniqueness of the isolates of this clade.

Clade two includes three isolates Saccharomyces cerevisiae, TCY1 (isolate 2), Cryptococcus humicolus (isolate 14), Kloeckera sp. (isolate 7). Saccharomyces cerevisiae, 2 and Cryptococcus humicolus, 14 are linked at a distance of 0.44 while they are joined to Kloeckera sp., 7 at a distance of 0.37 .

Primer six reorganized the isolates of clade four of primer one where isolate Kloeckera sp. (isolate 7). and C. krusei / inconspicua (isolate 13) were replaced by Geotrichum capitatum (isolates $8 \& 11$ ) incase of clade three of primer six, so clade three is represented by six isolates of $C$. norvegensis (isolate 5), Geotrichum capitatum (isolates $8 \& 11$ ), Kloeckera sp. (isolate 4), Candida famata (isolate 16 ), and C. krusei / incon- spicua (isolate 17). In clade three of primer six, $C$. norvegensis (isolate 5) and Geotrichum capitatum (isolate 11) are the most related to each other (joined by a distance of 0.70 ) followed by $\mathrm{Ge}$ otrichum capitatum (isolate 8 ) which is linked to C. norvegensis (isolate 5) and Geotrichum capitatum (isolate11) by a distance of 0.65 and 0.67 respectively (in case of primer one Geotrichum capitatum (isolates $8 \& 11$ ) were closely related at a distance of 0.62 representing clade two). The former three isolates are linked to isolate Kloeckera sp. (isolate 4), at a distance of 0.52, while all of the mentioned isolates are linked to Candida famata (isolate 16), and C. krusei / inconspicua (isolate 17) at an average distance of 0.3. Candida famata and C. krusei / inconspicua, (16 and 17) are the least linked of clade three (0.4). Isolate 13 representing another strain of C. krusei / inconspicua is linked to clade one at a distance of 0.04 while to clade two at 0.22 . Clade two and clade three are joined together at a distance of 0.30 .

\section{DISCUSSION}

Identification of microorganisms has changed dramatically over the past decade through direct examination of the tremendous variation present in 
DNA (McEwen et al 2000). Typing methods based on phenotypic characteristics are usually cheap and easy to perform but they have shown a lack in their reproducibility. On the contrary, genotypic methods are expensive and require sophisticated technology but they usually have good reproducibility (Del Castillo et al 1997).

In the current study RAPD-PCR procedure was used successfully along with the API biochemical kit as a research tool to identify and characterize yeast isolates from various locations. Corte et al (2005) stated that the combination of different typing techniques was useful when discriminating similar organisms. So, the introduction of a second typing technique can be more advantageous than increasing the number of characters obtained with a single method. Pina et al (2005) used the combination of PCRfingerprinting and RAPD assays to discriminate fifty-eight yeast isolates from carbonated orange juice factory that showed to be very useful in tracking the route of contamination in a carbonated juice production chain.

This study demonstrates that the identification of yeast isolates by their distinctive fingerprint pattern can be achieved in less than $10 \mathrm{hr}$ using RAPD-PCR technology. The procedure requires only a small amount of crudely extracted DNA from a single colony isolate. The method is not useful for the characterization of mixtures of unknowns, but single-colony isolates from a nutrient plate containing a mixed culture are sufficient for a clean fingerprint pattern. In food and beverage industry laboratories, of great significance is the time saved by analytical methods. The time required for identification of an isolate can be as short as $10 \mathrm{hr}$, which includes DNA extraction, RAPD amplification, and electrophoretic analysis. So, the technology is multifaceted in that it can be applied at any point along the brewing process.

RAPD-PCR produced a profile of bands that allowed the identification of intra- and interspecific polymorphisms among isolates. The technique was performed with each of the two primers as outlined in experimental. Both primers yielded strong distinctive patterns for the 16 yeast isolates while the number and sizes of the generated fragments being entirely differnt from one another. Rieseberg (1996) stated that primers with arbitrary sequences give different banding patterns with the same DNA even by applying on the same individual genotypes of species which may be obtained due to the recombination generating species.
Our study and those of others reported previously (King et al 1995; Thanos et al 1996; Lockhart et al 1997; Steffan et al 1997; Melo et al 1998; Cadez et al 2002; Vasdinyei and Deak, 2003; Fadda et al 2004; Foschino et al 2004 and Pinto et al 2004) have shown that RAPD methods performed with different oligonucleotides basically generated consistent patterns, with several shared fragments unique to each species. The use of different primers for the identification of the microorganisms increased the level of confidence of the identification.

According to the results obtained, RAPD fingerprinting, combined with API yeast identification system was useful when discriminating similar organisms. Additionally, it should be noted that the results of biochemical identification are very close to those of molecular characterization of primer 1 which grouped the isolated yeasts into clades very similar to those of biochemical identification. However, primer 6 was different from the API identification in a number of isolates where it grouped differently identified API isolates together confirming the need for more than one technique for identification and that biochemical identification is not enough. This is ensured by the percentage of error admitted worldwide for biochemical identification.

\section{REFERENCES}

Abbott, M.S. and M.J.A, Fedele (1994). DNAbased varietal identification procedure for hop leaf tissue. J. Inst. Brew.100: 283-285.

Abul-Hamd, A.T. (1999). Studies of Molecular Biology on Some Nitrogen Regulatory Genes in Saccharomyces cerevisiae. p. 35. Ph.D., Faculty of Science for boys, Al-Azhar Univ.

Anonymous. (1999). Molecular Analyst Software, Fingerprinting Plus and Fingerprinting Dst Software, Version 1.6, Instruction Manual. Bio-Rad Laboratories, Life Science Group, Hercules, Calif.

Baleiras Couto, M.M.; J.T.W.E. Vogels; H. Hofstra; J.H.J. Huis in't Veld and J.M.B.M. van der Vossen. (1995). Random amplified polymorphic DNA and restriction enzyme analysis of PCR amplified rDNA in taxonomy: two identification techniques for food-borne yeasts. J. Appl. Bacteriol. 79:525-535.

Baleiras Couto, M.M.; B. Eijsma; H. Hofstra; J.H.J. Huis in't Veld and J.M.B.M. van der Vossen (1996). Evaluation of molecular typing techniques to assign genetic diversity among Sac- 
charomyces cerevisiae strains. Appl. Environ. Microbiol. 62:41-46.

Cadez, N.; P. Raspor; A.W. de Cock; T. Boekhout and M.T. Smith (2002). Molecular identification and genetic diversity within species of the genera Hanseniaspora and Kloeckera. FEMS Yeast Res.1(4):279-289.

Corte, L.; M. Lattanzi; P. Buzzini; A. Bolano; F. Fatichenti and G. Cardinali (2005). Use of RAPD and killer toxin sensitivity in Saccharomyces cerevisiae strain typing. J. Appl. Microbiol. 99(3):609-617.

Deák, T. (1995). Methods for the rapid detection and identification of yeasts in foods. Trends Food Sci. Technol. 6:287-292.

Del Castillo, L.; J. Bikandi; A. Nieto; G. Quindós; R. Sentandreu and J. Pontón (1997). Comparison of morphotypic and genotypic methods for strain delineation in Candida. Mycoses 40: 445450.

DiMichele, L.J. and M.J. Lewis (1993). Rapid, species-specific detection of lactic acid bacteria from beer using the polymerase chain reaction. $\mathbf{J}$. Am. Soc. Brew. Chem. 51:63-66.

Esteve-Zarzoso, B.; C. Belloch; F. Uruburu and A. Querol (1999). Identification of yeasts by RFLP analysis of the 5.8S rRNA gene and the two ribosomal internal transcribed spacers. Int. J. Syst. Bacteriol. 49:329-337.

Espinel-Ingroff, A.; J.A. Vazquez; D. Boikov; M.A. Pfaller (1999). Evaluation of DNA-based typing procedures for strain categorization of Candida spp. Diagn. Microbiol. Infect. Dis. 33: 231-239.

Fadda, M.E.; V. Mossa; M.B. Pisano; M. Deplano and S. Cosentino (2004). Occurrence and characterization of yeasts isolated from artisanal Fiore Sardo cheese. Int. J. Food Microbiol. 95(1):51-59.

Foschino, R.; S. Gallina; C. Andrighetto; L. Rossetti; A. Galli (2004). Comparison of cultural methods for the identification and molecular investigation of yeasts from sourdoughs for Italian sweet baked products. FEMS Yeast Res. 4(6):609-618.

Fernández, M.; J.F. Ubeda and A.I. Briones (1999). Comparative study of non-Saccharomyces microflora of musts in fermentation, by physiological and molecular methods. FEMS Microbiol. Lett. 173:223-229.

Grando, M.S.; J. Ubeda and A.I. Briones (1994). RAPD analysis of wine Saccharomyces cerevisiae strains differentiated by pulsed field gel electrophoresis. Biotech. Tech. 8:557-560.
Guillamón, J.M.; J. Sabate; E. Barrio; J. Cano and A. Querol (1998). Rapid identification of wine yeast species based on RFLP analysis of the ribosomal internal transcribed spacer (ITS) region. Arch. Microbiol. 169:387-392.

King, D.; J. Rhine-Chalberg; M.A. Pfaller; S.A. Moser and W.G. Merz (1995). Comparison of four DNA-based methods for strain delineation of Candida lusitaniae. J. Clin. Microbiol. 33:14671470.

Ko, H.L. and R.J. Henry (1994). Identification of barley varieties using the polymerase chain reaction. J. Inst. Brew. 100:405-407.

Lehmann, P.F.; D. Lin, and B.A. Lasker (1992). Genotypic identification and characterization of species and strains within the genus Candida by using random amplified polymorphic DNA. J. Clin. Microbiol. 30:3249-3254.

Lieckfeldt, E.; W. Meyer and T. Borner (1993). Rapid identification and differentiation of yeasts by DNA and PCR fingerprinting. J. Basic Microbiol. 33(6):413-25.

Lockhart, S.R.; S. Joly; C. Pujol; J.D. Sobel; M.A. Pfaller and D.R. Soll (1997). Development and verification of fingerprinting probes for Candida glabrata. Microbiology 143:3733-3746.

McEwen, J.G.; J.W. Taylor; D. Carter; J. Xu; M.S. Felipe; R. Vilgalys; T.G. Mitchell; T. Kasuga; T. White; T. Bui and C.M. Soares (2000). Molecular typing of pathogenic fungi. Med. Mycol. (Suppl.) 38: 189-197.

Melo, A.S.; L.P. de Almeida; A.L. Colombo and M.R. Briones (1998). Evolutionary distances and identification of Candida species in clinical isolates by randomly amplified polymorphic DNA (RAPD). Mycopathologia 142:57-66.

Molnár, O.; R. Messner; H. Prillinger; U. Stahl and E. Slavikova (1995). Genotypic identification of Saccharomyces species using random amplified polymorphic DNA analysis. Syst. Appl. Microbiol. 18:136-145.

Odds, F.C.; D.L. Brawner; J. Staudinger; P.T. Magee and D.R. Soll (1992). Typing of Candida albicans strains. J. Med. Vet. Mycol. 30 (Suppl.): 87-94.

Pina, C.; P. Teixeiro; P. Leite; M. Villa; C. Belloch and L. Brito (2005). PCR-fingerprinting and RAPD approaches for tracing the source of yeast contamination in a carbonated orange juice production chain. J. Appl. Microbiol. 98(5): 1107-1114.

Pinto, P.M.; M.A. Resende; C.Y. Koga-Ito and M. Tendler (2004). Genetic variability analysis among clinical Candida spp. isolates using ran- 
dom amplified polymorphic DNA. Mem. Inst. Oswaldo Cruz. 99(2):147-52.

Prest, A.G.; J.R.M. Hammond and G.S.A.B. Stewart (1994). Biochemical and molecular characterization of Obesumbacterium proteus a common contaminant of brewery yeasts. Appl. Environ. Microbiol. 60:1635-1640.

Rieseberg, L.H. (1996). Homology among RAPD fragments in interspecific comparisons. Molecular Ecology 5: 99-105.

Robert, F.; F. Lebreton; M.E. Bougnoux; A. Paugam; D. Wassermann; M. Schlotterer; C. Tourte-Schaffer and J. Dupouy-Camet (1995). Use of random amplified polymorphic DNA as a typing method for Candida albicans in epidemiological surveillance of a Burn Unit. J. Clin. Microbiol. 33: 2366-2371.

Savard, L.; J.N.G. Hutchinson and T.M. Dowhanick (1994). Characterization of different isolates of Obesumbacterium proteus using random amplified polymorphic DNA. J. Am. Soc. Brew. Chem. 52:62-65.

Smole Mozina, S. and P. Raspor (1997). Molecular techniques for yeast identification in food processing. Food Technol. Biotechnol. 35: 5561.

Steffan, P.; J.A. Vázquez; D. Biokov; C. Xu; J.D. Sobell and R.A. Akins (1997). Identification of Candida species by randomly amplified polymorphic DNA fingerprinting of colony lysates. $\mathbf{J}$. Clin. Microbiol. 35:2031-2039.

Thanos, M.; G. Schönian; W. Meyer; C. Schweynoch; Y. Gräser; T.G. Mitchell; W. Presber and H.J. Tietz (1996). Rapid identifica- tion of Candida species by DNA fingerprinting with PCR. J. Clin. Microbiol. 34:615-621.

Tompkins, T.A.; R. Stewart; L. Savard; I. Russell and T.M. Dowhanick (1996). RAPD-PCR characterization of brewery yeast and beer spoilage bacteria. J. Am. Soc.Brew. Chem. 54:91-96.

Tsuchiya, Y.; Y. Kano and S. Koshino (1994). Identification of lactic acid bacteria using temperature gradient gel electrophoresis for DNA fragments amplified by polymerase chain reaction. J. Am. Soc. Brew. Chem. 52:95-99.

Valente, P.; F.C. Gouveia; G.A. Lemos; D. Pimentel; L.C. Mendonca-Hagler and A.N. Hagler (1997). PCR-amplified ITS length variation within the yeast genus Metschnikowia. J. Gen. Appl. Microbiol. 43:179-181

Van der Vossen, J.M.B.M. and H. Hofstra (1996). DNA based typing, identification and detection systems for food spoilage microorganisms: development and implementation. Int. J. Food Microbiol. 33:35-49.

Vasdinyei, $R$ and T. Deak (2003). Characterization of yeast isolates originating from Hungarian dairy products using traditional and molecular identification techniques. Int. J. Food Microbiol. 86(1-2):123-30.

Welsh, J. and M. McClelland (1990). Fingerprinting genomes using PCR with arbitrary primers. Nucleic Acids Res. 18:7213-7218.

Williams, J.G.K.; A.R. Kubeilk; K.J. Livak; J.A. Rafalski, and S.V. Tingey (1990). DNA polymorphism amplified by using specific and RAPD polymerase chain reaction. J. Am. Soc. Brew. Chem. 54:97-102. 